\title{
The Potential of Distributed
} Solar PV Capacity in Riyadh: A GIS-Assisted Study

\section{Abdelrahman Muhsen and Amro M Elshurafa}




\section{About KAPSARC}

The King Abdullah Petroleum Studies and Research Center (KAPSARC) is a non-profit global institution dedicated to independent research into energy economics, policy, technology and the environment across all types of energy. KAPSARC's mandate is to advance the understanding of energy challenges and opportunities facing the world today and tomorrow, through unbiased, independent, and high-caliber research for the benefit of society. KAPSARC is located in Riyadh, Saudi Arabia.

This publication is also available in Arabic.

\section{Legal Notice}

(C) Copyright 2019 King Abdullah Petroleum Studies and Research Center ("KAPSARC"). This Document (and any information, data or materials contained therein) (the "Document") shall not be used without the proper attribution to KAPSARC. The Document shall not be reproduced, in whole or in part, without the written permission of KAPSARC. KAPSARC makes no warranty, representation or undertaking whether expressed or implied, nor does it assume any legal liability, whether direct or indirect, or responsibility for the accuracy, completeness, or usefulness of any information that contain in the Document. Nothing in the Document constitutes or shall be implied to constitute advice, recommendation or option. The views and opinions expressed in this publication are those of the authors and do not necessarily reflect the official views or position of KAPSARC. 


\section{Key Points}

The upper limit for distributed generation solar power in Riyadh is evaluated using geographic information system (GIS) analysis.

By relying on land lot data for different categories, i.e., zones, and the maximum allowable area that could be built within a certain lot using prevailing building codes and regulations, the rooftop area suitable for PV deployment was estimated.

The total number of parcels included in the data set was around 1 million.

The analysis considered rooftops in residential, mosque, shopping mall, and health care buildings. The upper limit of rooftop solar PV capacity that can be deployed in the city of Riyadh was found to be 4.34 gigawatts (GW).

This capacity represents nearly $22 \%$ of the peak load and can satisfy approximately $9 \%$ of the energy requirement in the central region - the region in which Riyadh resides. 


\section{Summary}

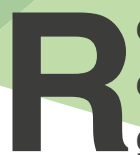

ooftop solar photovoltaic (PV) systems, commonly referred to as distributed

generation (DG) solar systems, can play a central role in the energy mix for sustainable cities. As with all forms of power generation, DG carries technical, financial, policy, and market implications that impact utilities, governments, businesses and other stakeholders. Therefore, quantifying the potential of DG for a given jurisdiction helps to inform the decision-making process for all involved.
To this end, this study quantifies the upper limit of rooftop PV systems that could be deployed in Riyadh, the capital of Saudi Arabia, using geographic information system (GIS) analysis. The study utilizes a data set of nearly 1 million land lots in combination with land-use categories, building types, and relevant building codes. The research finds a maximum potential capacity of 4.34 gigawatts (GW), representing nearly $22 \%$ of central Saudi Arabia's peak load and can satisfy approximately $9 \%$ of the region's total energy requirement. 


\section{Introduction}

G lobal demand for electricity is steadily rising. The International Energy Agency, in its 2018 World Energy Outlook, projects that global electricity demand will climb to at least 37,000 terawatthours (TWh) by 2040 from 25,700 TWh in 2017 (IEA 2018). Facing heightened environmental concerns (Panwar, Kaushik, and Kothari 2011), governments are under pressure to meet this demand while curbing fossil fuel use and carbon emissions (Cronshaw 2015). Therefore a considerable percentage of the required increase in supply is expected to be met by renewable energy technologies, including solar photovoltaics (PV) (Moriarty and Honnery 2016; Weitemeyer et al. 2015).

The solar PV industry has advanced rapidly over the past two decades. Strong policy support, financial and otherwise (Dusonchet and Telaretti 2015; Quitzow 2015), coupled with declining costs of PV technology (Elshurafa et al. 2018; Trappey et al. 2016) have contributed to the rapid deployment of PV. In less than two decades, the global installed capacity of solar PV jumped from no mentionable capacity in the early 2000 s to over $500 \mathrm{GW}$ by the end of 2018. In addition to requiring no fuel and being carbon-free once installed, solar PV enjoys low operation and maintenance costs. However, the technology suffers from being an intermittent (i.e., non-dispatchable) source.

Solar PV systems can be broadly categorized by capacity as residential $(2 \mathrm{~kW}-10 \mathrm{~kW})$, commercial (20 kW - $200 \mathrm{~kW})$, or utility-scale (1 MW and above). Residential and commercial systems are also classified as distributed generation (DG) systems (Kakran and Chanana 2018), indicating that these are installed within the distribution network or near the load (Ehsan and Yang 2018). DG systems are generally installed on rooftops but can also be ground-mounted if enough area is available.
However, utility-scale systems are always ground-mounted and require relatively large amounts of land.

DG and utility-scale systems each have strengths and weaknesses. Utility-scale solar farms benefit from economies of scale and are easier for electricity companies to manage from a central planning perspective (Dobrotkova, Surana, and Audinet 2018). However, land availability makes utility-scale deployment difficult in cities and nearly impossible within city centers.

DG systems, meanwhile, do not require significant land area and can provide direct economic and other benefits to individuals and businesses (Taşcıkaraoğlu 2018). Homeowners (or industrial facilities, for example) can reduce their utility bills by consuming the electricity produced by their DG systems. Furthermore, if DG owners can sell energy back to the grid, they can even turn a profit (Thopil et al. 2018). This consumer empowerment (Walters, Kaminsky, and Gottschamer 2018) transforms DG owners into so-called 'prosumers' (i.e., consumer-producers) and has particular appeal where prevailing electricity prices are high. On the other hand, DG systems could destabilize the distribution network (Jeong, Lee, and Alleman 2019) and thus require careful regulation by the authorities and new operating procedures by utility companies.

Governments that have promoted renewable energy have generally been motivated by three main drivers: reducing carbon emissions, increasing energy security, and boosting the economy by fostering renewable energy industries and adding jobs (Elshurafa, Farag, and Hobbs 2019). These objectives would be aided by setting overall capacity targets for renewable energy as well as targets for each renewable technology. This could be done as part of a wider renewable energy plan based 
on financial, legal, industrial, economic, trade and other considerations and the related impacts for key stakeholders.

One consideration that informs the decision of the utility-scale PV capacity to be installed is land availability, accessibility, and suitability (Bukhary, Ahmad, and Batista 2018). The latter relates to proximity to loads and transmission infrastructure (Deetjen et al. 2018), environmental concerns such as whether the land is a habitat for protected species (Visser et al. 2019) - and potential interference with agricultural or other activities (Semeraro et al. 2018). However, once an area is deemed suitable for a utility-scale project, it is easy to estimate the size of the solar farm that could be constructed with a high level of confidence.

It is harder, however, to assess the potential productivity of DG installations. Cities comprise residential buildings, shopping centers, government offices, places of worship, etc., with starkly different footprints and rooftops. Furthermore, different neighborhoods have widely varying electricity infrastructure capabilities and population densities, and thus different load consumption. As such, the potential for DG installation in urban locations will vary significantly (Mehigan et al. 2018), and trying to quantify this will help policymakers plan and budget for renewable energy targets, including the share that DG can contribute (da Silva et al. 2019).
In light of the above, we quantify, for the first time, the upper limit of solar DG potential in Riyadh, the capital of Saudi Arabia, using a geographic information system (GIS) approach. We rely on data for land lots, including size and dedicated use (e.g., residential, commercial, mosque, etc.), adjusted for relevant building code regulations, to determine the maximum area suitable for PV deployment in each lot. Based on the typical power-to-area ratio of solar PV modules, it was found that the maximum rooftop PV capacity that can be deployed in Riyadh is $4.34 \mathrm{GW}$, where this capacity includes residential, mosque, mall, and healthcare buildings only. This numerical finding is an upper limit, based on the efficiency of current PV technology, which does not account for economic or technical limitations.

This analysis is timely. Given that Saudi Arabia has ambitious renewable energy plans, and the electricity regulator has released provisional rules that will govern DG, including compensation for sales back to the grid, understanding the potential for DG in Riyadh will help the Kingdom to move forward with its renewable energy plans. 


\section{Review and Motivation}

$\mathrm{M}$ any governments have realized the potential for solar DG to meet growing electricity demand and help combat climate change. As mentioned above, DG offers greater value in highly dense and populous cities where land for utility-scale deployment is scarce.

Assessing the potential for DG deployment requires a range of factors to be considered, including spatial analysis. Accordingly, numerous studies involving both utility- and DG-scale systems rely heavily on GIS analysis. For utility-scale PV, GIS analysis can be a cost-effective and precise way to evaluate a potential site for solar farm construction (Huld et al. 2005; Mondal and Islam 2011). For DG system research, GIS analysis is more critical: while large plots of land can be easily measured using conventional methods, it is virtually impossible to conduct a macro-scale analysis of rooftops without GIS analysis.

Studies that involve GIS analysis and DG vary in scope and focus. Some analyze solar irradiation levels and other data for climatic conditions, such as dust and cloud cover, and allow electricity generation potential to be estimated for a given area (Sørensen 2001). Studies of this nature have been conducted for Africa (Huld et al. 2005), Bangladesh (Mondal and Islam 2011), and Slovakia (Hofierka and Cebecauer 2008), among other locations.

GIS analysis is also important in rural electrification studies (Azeem, Narejo, and Shah 2018). Rural areas throughout the world are mostly powered by diesel generation, which is expensive and presents other significant disadvantages including carbon pollution, noise pollution, diesel price fluctuation, diesel transportation/delivery costs, and the risk of supply disruptions (Monyei, Adewumi, and Jenkins 2018). For large and difficult to monitor rural zones, GIS analysis proves to be a vital tool for energy planning (Rosas-Flores, Rosas-Flores, and Zayas 2016; Van Hoesen and Letendre 2010) and PV system fault detection (de Simón-Martín et al. 2017).

As mentioned, DG requires different engineering considerations and new modes of operation by utility companies. GIS analysis has been used in technical studies to ensure that the placement of DG systems satisfies certain technical objectives such as voltage profile improvement (Sadeghian, Athari, and Wang 2017) and loss minimization (Jamil and Anees 2016). GIS analysis has also been used to complement supply and demand studies to offset peak loads and improve grid stability (Camargo et al. 2015).

Furthermore, GIS has been employed in socioeconomic and behavioral research on topics such as DG adoption rates, i.e., diffusion, in neighborhoods. When one household installs a rooftop PV system, neighbors may be more likely to do the same. This phenomenon has been studied by coupling GIS analysis and agent-based modeling to describe the diffusion of $D G$ and how the perception and behavior of neighbors toward PV may change if a nearby house installs a system (Muaafa et al. 2017; Robinson et al. 2013).

There are at least three key types of stakeholders that would be interested in understanding the potential for solar power generation within a city, state/province, or country. First, policymakers need to know what capacity of utility-scale and/ or DG-scale systems could potentially be installed in order to plan and budget (Picciariello et al. 2015). This also informs critical estimates for new employment opportunities and other economic benefits. Second, grid operators and/or the electricity utilities should know how much additional capacity could be introduced into the system in order to better plan for grid upgrades and ramping capabilities (Adefarati and Bansal 2016). This also 
allows them to evaluate the financial implications of customers buying less electricity from the grid (Prehoda, Pearce, and Schelly 2019). Third, companies that sell and/or install PV systems benefit from understanding market-wide potential PV capacity as they use this knowledge to evaluate their business opportunities (Zhang et al. 2015).

Given the impact that capacity estimation of DG deployment can have on key decisions, it is unsurprising that this topic has been the focus of much research. For example, a study of the solar energy generation potential for rooftops in Hong Kong was estimated to be 2.66 TWh per year, based on an integrated analysis using GIS, solar irradiation data, and remote sensing technologies (Wong et al. 2016). On a much smaller scale, a simulation framework using GIS analysis was developed to optimally size and locate solar PV in a campus environment (Kucuksari et al. 2014).

A more sophisticated study was performed for Dhaka, Bangladesh, in which the authors considered the capacity of substations available in neighborhoods of interest (Jamal et al. 2014). The rooftop area suitable for DG installation was estimated for several parts of Dhaka using GIS analysis, coupled with light detection and ranging technology (i.e., LiDAR). A similar study was conducted for Georgetown, Malaysia that added a layer of detail by identifying which roofs were facing south and measuring their slopes (Latif, Zaki, and Salleh 2012).
GIS can also be used to estimate the potential of solar PV deployment for entire countries. The National Renewable Energy Laboratory in the United States (U.S.) analyzed the technical potential of renewable energy generation technologies while considering resource availability, topography, and constraints associated with land use (Lopez et al. 2012). Besides solar PV, the study examined onshore and offshore wind, hydropower and geothermal technologies. The study concluded that around $664 \mathrm{GW}$ of rooftop solar could be installed in the U.S., compared with 154 TW of utility-scale PV.

Having shown that GIS analysis is a reliable tool to assess the potential for DG deployment, it is worth noting the two key motivations for this study. The first was the Saudi Arabian government's ambitious renewable energy plans. Currently, there is no mentionable DG installed capacity in the Kingdom. Secondly, Saudi Arabia embarked on significant energy price reforms that have raised electricity prices twice in the past few years, and further hikes are possible. This makes DG an increasingly attractive option for households, especially as technology costs drop and liberalized regulations allow electricity to be sold back to the grid. In anticipation of accelerating PV installation, the Saudi regulator the Electricity \& Co-Generation Regulatory Authority (ECRA) has issued bylaws for how DG will be governed. 


\section{Method}

audi Arabia lies in the southwestern corner of Asia and is the largest country by land area in the Middle East. Riyadh, its capital, has a population of over 7 million. The country has excellent potential for solar power generation, with global horizontal irradiance (GHI) in Riyadh averaging about 2,200 kWh per square meter (m2) per year, which is considered significantly high (Zell et al. 2015). Riyadh is therefore a strong candidate for DG installations. For comparison, Southern Germany, for example, possesses an average GHI of about 1,200 kWh/m2/year.

\section{Data and scoping}

Ideally, it is desirable to employ high-resolution aerial imagery or LiDAR data to identify and quantify suitable roof space that satisfies the requirements of solar PV installation and mounting. Unfortunately, no such resources are readily available for Riyadh.
Instead, this study relies on statistics for land lots, also referred to as land parcels, as identified in land-use and zoning datasets. A land lot can be defined as a distinct area of land demarcated for a specific purpose according to official zoning. Designations include residential, commercial, industrial, and governmental.

A GIS layer for Riyadh, representing parcel-lots and their designations, was obtained from the Riyadh Development Authority (http://rda.gov. sa). This provides a static snapshot of land-use codes in Riyadh for 2016, and includes a spatial representation (i.e., location and shape) of every one of the city's nearly 1 million lots. Each parcel is assigned a land-use code based on zoning regulations and labeled by building type (or otherwise as vacant). Possible land-use codes and building types are detailed in tables 1 and 2, respectively.

Table 1. Unique land-use codes.

\section{Land-use codes}

\begin{tabular}{l} 
Residential \\
\hline Industrial \\
\hline Storage and warehouse \\
\hline Transport services \\
\hline Communication and public services \\
\hline Commercial \\
\hline Business services \\
\hline Government services \\
\hline Cemeteries \\
\hline Healthcare \\
\hline Education services \\
\hline Mosques \\
\hline Social and cultural \\
\hline Amusement and parks \\
\hline Agricultural \\
\hline Vacant
\end{tabular}

Source: Authors' Analysis. 
Table 2. Unique building types.

\section{Building types}

\begin{tabular}{l} 
Tent or cottage \\
\hline Traditional Arabic house \\
\hline Villa \\
\hline Mansion \\
\hline Apartment building \\
\hline Urban building \\
\hline Office building \\
\hline Commercial/retail building \\
\hline Market \\
\hline Warehouse \\
\hline Factory \\
\hline Public service \\
\hline Complex/unknown building type \\
\hline Mixed use (not in a multistory building) \\
\hline Mixed use (in a multistory building) \\
\hline Commercial center \\
\hline Oacant
\end{tabular}

Source: Authors' Analysis.

Figure 1. A sample of the geographical data available for a neighborhood in northern Riyadh. Note: (a) shows the neighborhood as it appears in satellite imagery using the ArcGIS base-map; (b) the same area is categorized as land parcels color-coded by zonal designation. For example, yellow represents residential land lots and light blue are educational institution lots.

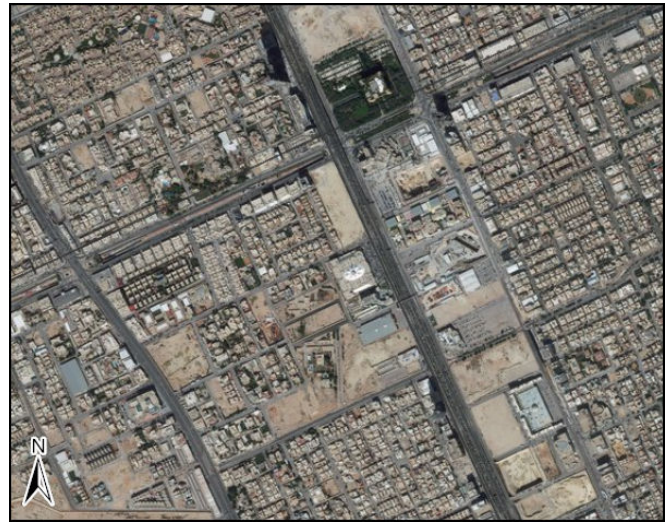

(a)

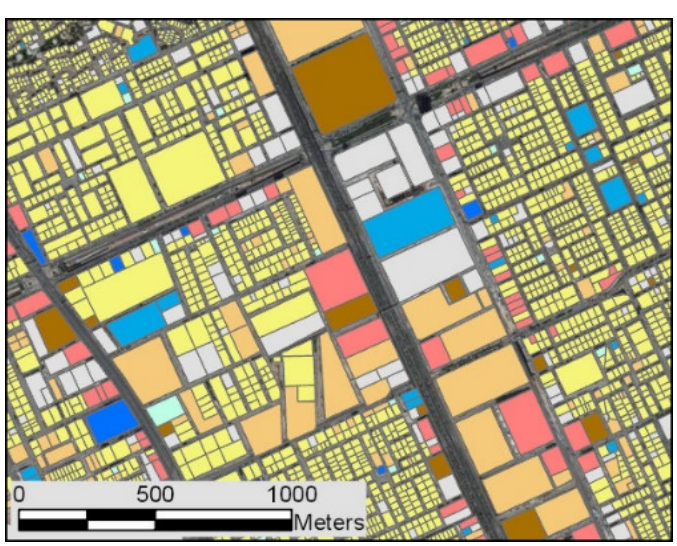

Residential

Commercial

Educational

Vacant

Government

Mosques

Healthcare

Other

(b)

Source: Authors' Analysis. 
The land-use GIS layer has been analyzed using the commercially available software ArcGIS Pro. In addition to visualizing and interrogating the layer, the application allowed the land-use data to be supplemented with additional attributes. Most importantly, the geo-processing engine of ArcGIS Pro was used to derive the area of parcels in square meters. Then, the resulting data was exported into tabular form to be processed via Python scripting language. For more information about this post-processing, please refer to Appendix A.

Figure 1 shows a snapshot of geographical data: a raw image of a neighborhood in Riyadh is shown in Figure 1a, and the corresponding zoning categorization is displayed using color codes in Figure 1b. Note how each land parcel is color-coded for ease of identification. For more details, please refer to Appendix A.

Because this paper focuses on rooftop DG, some land parcel categories listed in Table 1 will be excluded from the analysis for the following reasons:

Inapplicability: Land parcels denoted as agricultural, amusement and parks, cemeteries, and transport services (i.e., parking) would generally not qualify as suitable for DG installation, as these parcels will generally contain no, or few, buildings.

Broad activities: The same category may be representative of a number of activities that result in the land containing widely varying densities of buildings, or none at all. For example, the government services category can include tightly packed office buildings or open land for military bases and training camps.
Actual built-area variability: The variability of built areas within the same category can be significant. For example, in the educational services category, which includes schools, colleges, and universities, rooftop areas can vary widely depending on how land is utilized (number of buildings, presence and size of playgrounds, indoor sports court, parking, etc.).

\section{Lack of structural preparedness: Although} a building may exist, the roof may not be structurally suitable. For example, the storage and warehouse category often contains structures with metal sheet roof incapable of supporting PV installations. The same rationale applies for tents.

Therefore, this study analyzes the following four categories: three main categories - residential, mosque, and health services - plus commercial centers, a sub-category of commercial that will be referred to as 'malls.'

\section{Rooftop area and PV capacity calculation}

Land lots are never completely occupied. Building codes or other regulations require structures to be a minimum distance away from streets and other property boundaries. This is referred to as the land-use 'setback' and is normally implemented by local governments or other authorities to ensure architectural uniformity, access around the building, exposure to sunlight, and availability of space for landscaping, among other reasons.

Accordingly, building codes also specify the maximum allowable area that can be built (MAAB) within a land parcel. As with setback, MAAB varies across categories. For this paper, MAAB constitutes a realistic estimate for the maximum possible rooftop area that can exist in any parcel. 
However, a PV system cannot generally be deployed to fully cover a rooftop. A roof may be overly sloped or covered with shingles that inhibit PV installation. Parts of the roof may be unavailable due to satellite dishes, water tanks, clothes lines, air conditioners, ducts, among other items, while other sections may be too shaded by adjacent buildings or other obstructions to sunlight for PV (Khan, Asif, and Stach 2017). As expected, detailed information is not available for every building. Accordingly, this study employs a sensitivity analysis to estimate the variation between buildings in terms of the portion of the rooftop area that can support PV installation.
The potential PV capacity for each lot can be estimated using the area of each land parcel and its MAAB, plus an assumption regarding the rooftop area that can be utilized for solar modules. The size of the PV system that can be installed would depend on the power rating of the modules used (i.e., Watts $(\mathrm{W}) / \mathrm{m} 2$ ) and the angle at which they are mounted. Because Saudi Arabia lies in the northern hemisphere, the calculations in this paper assume that the modules are installed facing south at an angle of 25 degrees with the horizon. 


\section{Results and Discussion}

\section{Rooftop area calculations}

A summary of the land parcel data used to calculate the PV deployment potential is included in Table 3. It includes the four categories deemed suitable for this analysis: residential, mosques, healthcare and malls. Each category was sub-categorized, if needed, to allow for differences in MAAB or the percentage of the roof that could be utilized. For all sub-categories, a mean area was calculated to serve as an indicator of the validity of the obtained analysis.

The residential segment was divided into three sub-categories: villa, apartment building, and mansion. Note that the mean value for the villa segment is significantly lower than that of the mansion, as expected. Similarly, the mosque segment comprises small and large categories, where the former represents those that serve for daily prayers, and the latter those that hold Friday congregations and other social and festive activities. Lastly, the category of healthcare contains public hospitals, private hospitals, and clinics (i.e., small healthcare centers). Since malls is already a sub-category of the commercial category, it was not subdivided.

MAAB data was obtained from the Saudi Authority for Industrial Cities and Technology Zones (www. modon.gov.sa). Note that all MAAB values are $60 \%$ for all building types except mansions and clinics. The percentages of the roof that are available for PV deployment was obtained from Khan, Asif, and Stach (2017). We have used two scenarios for the available area of the rooftop: an optimistic scenario, where the portion of the roof available for PV deployment is high, and a conservative scenario, where it is low. These two extremes provide policymakers with a realistic range for the potential capacity that can be installed in Riyadh. The optimistic and conservative ratios are both used to calculate a median value for potential PV deployment.

From the total land parcel area, the maximum rooftop area that would be available can be estimated with the MAAB. Then, the percentage of the roof that can be used for PV installation would be a share of this maximum rooftop area available. All these calculations are summarized in Table 3. 


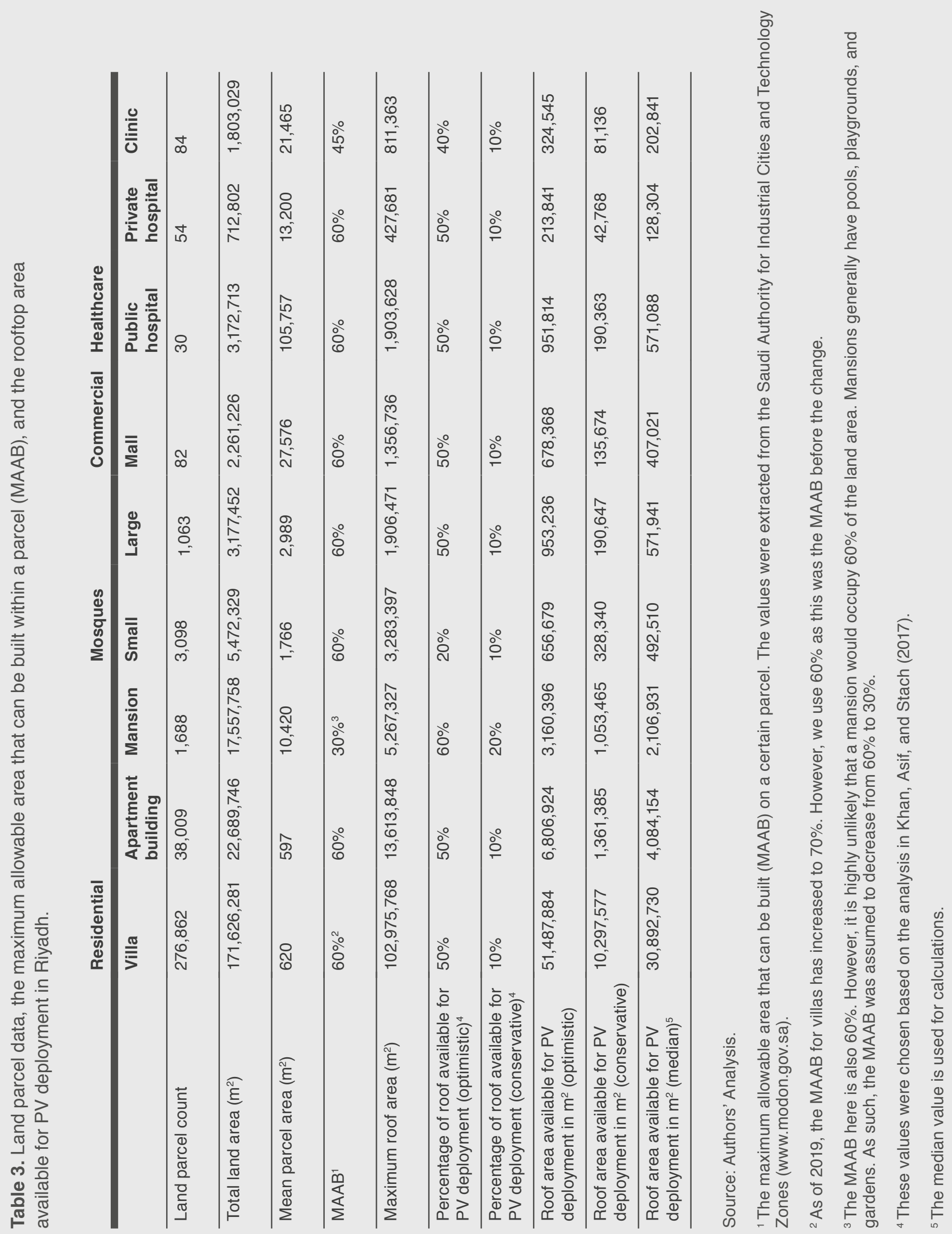




\section{PV Capacity calculations}

Table 3 summarizes the available area that is suitable for $\mathrm{PV}$ installation in each category based on the land parcel, the MAAB, and the percentage of the roof that could be utilized for deployment. For convenience and ease of reference, the median areas for all zones (i.e., the last row in Table 3) are summarized separately in Table 4. As can be seen, the total rooftop area available for DG installation in Riyadh is nearly 39.5 million square meters. Recall that this area results from the median values that were calculated from Table 3. As expected, we also note that the residential sector is responsible for nearly all the available area. Within the residential category, the villa sub-category contributes the largest share.
Having estimated the rooftop area available for PV installation, the corresponding PV capacity can be calculated. However, this depends on the module(s) that will be used and how they are installed. Most importantly, two or more rows of modules, i.e., strings, should be separated by a minimum distance to ensure that sunlight is not blocked, and also to allow access for maintenance and cleaning purposes.

Module capacity and sizes vary across manufacturers. By consulting the specification sheets for a number of PV module manufacturers worldwide, it was found that the power to area ratio typically ranges from 0.15 to $0.2 \mathrm{~kW} / \mathrm{m} 2$. This ratio excludes the separating distance between strings as mentioned above; it also does not account for

Table 4. The available area for PV installations in Riyadh and their potential PV capacities. Discrepancies are due to rounding.
Land parcel
Land parcel subcategory
Area (m2)
PV capacity (MW) that can be category

\begin{tabular}{l|l|l|l}
\multirow{2}{*}{ Residential } & Villa & $30,892,730$ & 3,398 \\
\cline { 2 - 4 } & Apartment building & $4,084,154$ & 449 \\
\cline { 2 - 4 } & Mansion & $2,106,931$ & 232 \\
\cline { 2 - 4 } & Residential total & $37,083,816$ & 4,079 \\
\hline \multirow{2}{*}{ Mosque } & Small & 492,510 & 54 \\
\cline { 2 - 4 } & Large & 571,941 & 63 \\
\cline { 2 - 4 } & Mosque total & $1,064,451$ & 117 \\
\hline \multirow{2}{*}{ Healthcare } & Mall & 407,021 & 45 \\
\cline { 2 - 4 } & Mall total & 407,021 & 45 \\
\cline { 2 - 4 } & Public hospital & 571,088 & 63 \\
\cline { 2 - 4 } & Private hospital & 128,304 & 14 \\
\cline { 2 - 4 } & Clinic & 202,841 & 22 \\
\hline & Grand total & $39,457,521$ & 4,340
\end{tabular}

Source: Authors' Analysis. 
the area required to install the inverter necessary to transform the direct current generated by the modules to an alternating current. Assuming a separating distance of 1 meter between strings, the power to area ratio drops to the range of 0.10 to 0.12 $\mathrm{kW} / \mathrm{m} 2$.

Using the areas in Table 4 and a median value of $0.11 \mathrm{~kW} / \mathrm{m} 2$ as the power to area ratio, the potential PV capacity that could be deployed is $4,340 \mathrm{MW}$ (or 4.34 GW) (shown in the right-hand column). The residential sector contributes most to this capacity, as expected, because it contains the largest rooftop area among the sectors considered.

\section{Contextualizing the results: A power system perspective}

Based on the analysis presented in this paper, Riyadh can deploy a maximum capacity of $4.34 \mathrm{GW}$ of rooftop PV systems. To contextualize this finding, it is useful to review the current power generation profile of Saudi Arabia, and more specifically, of the central region, where Riyadh sits.

According to ECRA, the peak load of the central region is $20 \mathrm{GW}$, more than its $16 \mathrm{GW}$ generation capacity (ECRA 2017). The deficit in supply is shouldered by the generation capacity available in the eastern region. Given that the demand generally correlates with ambient temperatures (i.e., hot temperatures increase the use of air conditioners), DG systems can help narrow the gap between load and available generation in the central region. However, many utilities do not view renewable power sources as firm capacity.

The energy consumption in the central region totaled $91 \mathrm{TWh}$. The share that the DG systems can provide can be calculated via (1) the rooftop area arrived at in the previous section, or (2) the maximum capacity of PV systems that could be deployed. Using the rooftop area previously calculated, i.e., 39.46 million $\mathrm{m} 2$, and a solar irradiation value of 2,200 kWh/m2/year, annual generation can be computed as $8.46 \mathrm{TWh}$. This assumes a module efficiency of $15 \%$, and an aggregate loss factor of 35\% for the PV system that accounts for losses from the inverter, cables, soiling, temperature, maintenance down time, and other factors (Khan, Asif, and Stach 2017).

Alternatively, the annual generation can be computed from an estimate of maximum PV capacity, calculated in this study to be $4.34 \mathrm{GW}$. Assuming a capacity factor of $21.4 \%$ (Baras et al. 2012), the annual generation becomes 8.14 TWh, which is comparable to the value calculated above using the available area. This is equivalent to nearly $9 \%$ of the total load of the central region.

\section{Contextualizing the results: Upper limit vs. pragmatic considerations}

The analysis presented in this paper yields an upper limit for the potential capacity of rooftop PV systems in Riyadh. Because DG deployment will face a variety of other constraints, this should not be seen as a practical limit or target.

Among the largest obstacles to DG deployment are infrastructure preparedness and whether the utilities can accommodate the difficult to control nature of PV rooftop generation. Quantifying the power losses associated with DG in order to assess network efficiency is an important step that helps to optimize performance (Li, Cui, and Li 2019).

Another obvious impediment for average households is the large upfront cost. A $5 \mathrm{~kW}$ residential PV system, for example, at $\$ 1.5 / \mathrm{W}$, would cost $\$ 7,500$ - a huge amount for many families. Coupled with the infrastructure 
preparedness issues cited above, this could create a scenario in which DG deployment ends up concentrated mainly in affluent neighborhoods, especially since wealthier families also tend to have larger homes with greater rooftop areas, making them better suited for PV installation.

Electricity providers can predict such deployment patterns, and the resulting capacity in specific areas, with the same methodology implemented in this paper. It is also important to note that residents who rent rather than own their homes are very unlikely to invest in PV since they will generally be unable to reap the long-term financial benefits.

Furthermore, in some instances, the rooftop area may be available, but the homeowner may be adopting a not-in-my-back-yard or 'NIMBY' behavior (Tidwell, Tidwell, and Nelson 2018). This has been witnessed in many countries and describes how individuals conceive of and interact with technology. Finally, we note that in many cases, a homeowner will opt not to install a rooftop solar system due to aesthetic objections. 


\section{Conclusions}

his paper has quantified the potential solar rooftop photovoltaic (PV) capacity that can be installed in Riyadh. By analyzing data for residential, mosques, malls, and healthcare buildings, it was found that the city's rooftops have a maximum DG capacity of around $4.34 \mathrm{GW}$. This is significant as the central region, where Riyadh lies, has a peak load requirement of $20 \mathrm{GW}$. At a capacity factor of $21.4 \%$, the calculated capacity would meet nearly $9 \%$ of the energy needs of the central region.
However, the maximum potential calculated in this paper is not to be confused with a pragmatic limit or target. As expected, various factors will hinder achieving such a capacity, including technical grid limitations, homeowner financial constraints, and aesthetic considerations. These and other factors mean the actual capacity that can be deployed is significantly lower than the calculated upper limit. Building upon the results presented in this paper, more detailed spatial analysis can be conducted for neighborhoods and areas that exhibit high readiness for PV deployment. 


\section{References}

Adefarati, T. and R.C. Bansal. 2016. "Integration of renewable distributed generators into the distribution system: a review." IET Renewable Power Generation no. $10(7): 873-884$.

Azeem, Fawad, Ghous Bakhsh Narejo, and Usman Ali Shah. 2018. "Integration of renewable distributed generation with storage and demand side load management in rural islanded microgrid." Energy Efficiency:1-19.

Baras, Abdulaziz, Wail Bamhair, Yahya AlKhoshi, Maher Alodan, and Jill Engel-Cox. 2012. "Opportunities and challenges of solar energy in Saudi Arabia." Paper read at World Renewable Energy Forum," Denver.

Bukhary, Saria, Sajjad Ahmad, and Jacimaria Batista. 2018. "Analyzing land and water requirements for solar deployment in the Southwestern United States." Renewable and Sustainable Energy Reviews 82:3288-3305.

Camargo, Luis Ramirez, Roland Zink, Wolfgang Dorner, and Gernot Stoeglehner. 2015. "Spatio-temporal modeling of roof-top photovoltaic panels for improved technical potential assessment and electricity peak load offsetting at the municipal scale." Computers, Environment and Urban Systems 52:58-69.

Chung, Donald, Carolyn Davidson, Ran Fu, Kristen Ardani, and Robert Margolis. 2015. US photovoltaic prices and cost breakdowns. Q1 2015 benchmarks for residential, commercial, and utility-scale systems. National Renewable Energy Lab. (NREL), Golden, CO (United States).

Cronshaw, Ian. 2015. "World Energy Outlook 2014 projections to 2040: natural gas and coal trade, and the role of China." Australian Journal of Agricultural and Resource Economics 59 (4):571-585.

da Silva, Patrícia Pereira, Guilherme Dantas, Guillermo Ivan Pereira, Lorrane Câmara, and Nivalde J. De Castro. 2019. "Photovoltaic distributed generation - An international review on diffusion, support policies, and electricity sector regulatory adaptation." Renewable and Sustainable Energy Reviews 103:30-39. de Simón-Martín, Miguel, Ana-María Diez-Suárez, Laura Álvarez-de Prado, Alberto González-Martínez, Álvaro De La Puente-Gil, and Jorge Blanes-Peiró. 2017. "Development of a GIS tool for high precision PV degradation monitoring and supervision: Feasibility analysis in large and small PV plants." Sustainability 9 (6):965.

Deetjen, Thomas A., Henry Martin, Joshua D Rhodes, and Michael E Webber. 2018. "Modeling the optimal mix and location of wind and solar with transmission and carbon pricing considerations." Renewable Energy 120:35-50.

Dobrotkova, Zuzana, Kavita Surana, and Pierre Audinet. 2018. "The price of solar energy: Comparing competitive auctions for utility-scale solar PV in developing countries." Energy Policy 118:133-148.

Dusonchet, L, and E Telaretti. 2015. "Comparative economic analysis of support policies for solar PV in the most representative EU countries." Renewable and Sustainable Energy Reviews 42:986-998.

Ehsan, Ali, and Qiang Yang. 2018. "Optimal integration and planning of renewable distributed generation in the power distribution networks: A review of analytical techniques." Applied Energy 210:44-59.

Electricity and Cogeneration Authority (ECRA). 2017. Annual Statistical Booklet for Electricity and Seawater Desalination Industries, Riyadh.

Elshurafa, Amro M., Shahad R. Albardi, Simona Bigerna, and Carlo Andrea Bollino. 2018. "Estimating the learning curve of solar PV balance-of-system for over 20 countries: Implications and policy recommendations." Journal of Cleaner Production 196:122-134.

Elshurafa, Amro M., Hind M. Farag, and David A. Hobbs. 2019. "Blind spots in energy transition policy: Case studies from Germany and USA." Energy Reports 5:20-28. 


\section{References}

Hofierka, Jaroslav, and Tomáš Cebecauer. 2008. "Spatially distributed assessment of solar resources for energy applications in Slovakia." Acta Facultatis Studiorum Humanitatis et Naturae Universitatis Prešoviensis. Prírodné vedy, Folia Geographica 12:97-114.

Huld, Thomas, Marcel Suri, Ewan Dunlop, Michel Albuisson, and Lucien Wald. 2005. "Integration of Helioclim-1 database into PV-GIS to estimate solar electricity potential in Africa." Paper read at Proceedings, 20th European Photovoltaic Solar Energy Conference.

International Energy Agency (IEA). 2018. World Energy Outlook 2018. Paris: International Energy Agency. ISBN: 978-92-64-30677-6.

Jamal, Taskin, Weerakorn Ongsakul, Jay Govind Singh, Sayedus Salehin, and S.M. Ferdous. 2014. "Potential rooftop distribution mapping using Geographic Information Systems (GIS) for Solar PV Installation: A case study for Dhaka, Bangladesh." Paper read at 2014 3rd International Conference on the Developments in Renewable Energy Technology (ICDRET).

Jamil, Majid, and Ahmed Sharique Anees. 2016. "Optimal sizing and location of SPV (solar photovoltaic) based MLDG (multiple location distributed generator) in distribution system for loss reduction, voltage profile improvement with economical benefits." Energy 103:231-239.

Jeong, Yu-Cheol, Eul-Bum Lee, and Douglas Alleman. 2019. "Reducing voltage volatility with step voltage regulators: A life-cycle cost analysis of Korean solar photovoltaic distributed generation." Energies 12 (4):652.

Kakran, Sandeep, and Saurabh Chanana. 2018. "Smart operations of smart grids integrated with distributed generation: A review." Renewable and Sustainable Energy Reviews 81:524-535.

Khan, Mohammed, Muhammad Asif, and Edgar Stach. 2017. "Rooftop PV potential in the residential sector of the Kingdom of Saudi Arabia." Buildings 7 (2):46.
Kucuksari, Sadik, Amirreza M Khaleghi, Maryam Hamidi, Ye Zhang, Ferenc Szidarovszky, Guzin Bayraksan, and Young-Jun Son. 2014. "An Integrated GIS, optimization and simulation framework for optimal PV size and location in campus area environments." Applied Energy 113:1601-1613.

Latif, Zulkiflee Abd, Nurul Ain Mohd Zaki, and Siti Aekbal Salleh. 2012. "GIS-based estimation of rooftop solar photovoltaic potential using LiDAR." Paper read at 2012 IEEE 8th International Colloquium on Signal Processing and its Applications.

Li, Hongmei, Hantao Cui, and Chunjie Li. 2019. "Distribution network power loss analysis considering uncertainties in distributed fenerations." Sustainability 11 (5):1311.

Lopez, Anthony, Billy Roberts, Donna Heimiller, Nate Blair, and Gian Porro. 2012. "US renewable energy technical potentials: A GIS-based analysis." NREL.

McCormick, P.G., and H. Suehrcke. 2018. "The effect of intermittent solar radiation on the performance of PV systems." Solar Energy no. 171:667-674.

McPherson, Madeleine, and Bryan Karney. 2017. "A scenario-based approach to designing electricity grids with high variable renewable energy penetrations in Ontario, Canada: Development and application of the SILVER model." Energy no. 138:185-196.

Mehigan, L, JP Deane, BP Ó Gallachóir, and V Bertsch. 2018. "A review of the role of distributed generation (DG) in future electricity systems." Energy.

Mondal, Md. Alam Hossain, and AKM Sadrul Islam. 2011. "Potential and viability of grid-connected solar PV system in Bangladesh." Renewable Energy 36 (6):1869-1874.

Monyei, C.G., A.O. Adewumi, and K.EH. Jenkins. 2018. "Energy (in) justice in off-grid rural electrification policy: South Africa in focus." Energy Research \& Social Science 44:152-171. 
Moriarty, Patrick, and Damon Honnery. 2016. "Can renewable energy power the future?" Energy Policy 93:3-7.

Muaafa, Mohammed, Iqbal Adjali, Patrick Bean, Rolando Fuentes, Steven O. Kimbrough, and Frederic H. Murphy. 2017. "Can adoption of rooftop solar panels trigger a utility death spiral? A tale of two US cities." Energy Research \& Social Science 34:154-162.

Panwar, N.L., S.C. Kaushik, and Surendra Kothari. 2011. "Role of renewable energy sources in environmental protection: A review." Renewable and Sustainable Energy Reviews 15 (3):1513-1524.

Picciariello, Angela, Claudio Vergara, Javier Reneses, Pablo Frías, and Lennart Söder. 2015. "Electricity distribution tariffs and distributed generation: Quantifying cross-subsidies from consumers to prosumers." Utilities Policy 37:23-33.

Prehoda, Emily, Joshua M. Pearce, and Chelsea Schelly. 2019. "Policies to overcome barriers for renewable energy distributed generation: A Case study of utility structure and regulatory regimes in Michigan." Energies $12(4): 674$

Quitzow, Rainer. 2015. "Dynamics of a policy-driven market: The co-evolution of technological innovation systems for solar photovoltaics in China and Germany." Environmental Innovation and Societal Transitions $17: 126-148$

Ranalli, J., K. Calvert, M. Bayrakci Boz, and J.R.S. Brownson. 2018. " Toward comprehensive solar energy mapping systems for urban electricity system planning and development." The Electricity Journal 31 (1):8-15.

Robinson, Scott A., Matt Stringer, Varun Rai, and Abhishek Tondon. 2013. "GIS-integrated agent-based model of residential solar PV diffusion." Paper read at 32nd USAEE/IAEE North American Conference.

Rosas-Flores, Jorge Alberto, Dionicio Rosas-Flores, and José Luis Fernández Zayas. 2016. "Potential energy saving in urban and rural households of Mexico by use of solar water heaters, using geographical information system." Renewable and Sustainable Energy Reviews 53:243-252.

Sadeghian, Hamidreza, Mir Hadi Athari, and Zhifang Wang. 2017. "Optimized solar photovoltaic generation in a real local distribution network." Paper read at 2017 IEEE Power \& Energy Society Innovative Smart Grid Technologies Conference (ISGT).

Semeraro, Teodoro, Alessandro Pomes, Cecilia Del Giudice, Danilo Negro, and Roberta Aretano. 2018. "Planning ground based utility scale solar energy as green infrastructure to enhance ecosystem services." Energy Policy 117:218-227.

Sørensen, Bent. 2001. "GIS management of solar resource data." Solar Energy Materials and Solar Cells 67 (1-4):503-509.

Taşcıkaraoğlu, Akın. 2018. "Economic and operational benefits of energy storage sharing for a neighborhood of prosumers in a dynamic pricing environment." Sustainable Cities and Society 38:219-229.

Thopil, M.S., R.C. Bansal, L. Zhang, and G. Sharma. 2018. "A review of grid connected distributed generation using renewable energy sources in South Africa." Energy Strategy Reviews 21:88-97.

Tidwell, Jacqueline, Abraham Tidwell, and Steffan Nelson. 2018. "Surveying the Solar Power Gap: Assessing the Spatial Distribution of Emerging Photovoltaic Solar Adoption in the State of Georgia, USA." Sustainability 10 (11):4117.

Trappey, Amy J.C., Charles V. Trappey, Hao Tan, Penny HY Liu, Shin-Je Li, and Lee-Cheng Lin. 2016. "The determinants of photovoltaic system costs: an evaluation using a hierarchical learning curve model." Journal of Cleaner Production 112:1709-1716.

Van Hoesen, John, and Steven Letendre. 2010. "Evaluating potential renewable energy resources in Poultney, Vermont: A GIS-based approach to supporting rural community energy planning." Renewable Energy 35 (9):2114-2122. 
Visser, Elke, Vonica Perold, Samantha Ralston-Paton, Alvaro C. Cardenal, and Peter G. Ryan. 2019. "Assessing the impacts of a utility-scale photovoltaic solar energy facility on birds in the Northern Cape, South Africa." Renewable Energy 133:1285-1294.

Walters, Jeffrey, Jessica Kaminsky, and Lawrence Gottschamer. 2018. "A systems analysis of factors influencing household solar PV adoption in Santiago, Chile." Sustainability 10 (4):1257.

Weitemeyer, Stefan, David Kleinhans, Thomas Vogt, and Carsten Agert. 2015. "Integration of Renewable Energy Sources in future power systems: The role of storage." Renewable Energy 75:14-20.

Wong, Man Sing, Rui Zhu, Zhizhao Liu, Lin Lu, Jinqing Peng, Zhaoqin Tang, Chung Ho Lo, and Wai Ki Chan. 2016. "Estimation of Hong Kong's solar energy potential using GIS and remote sensing technologies." Renewable Energy 99:325-335.
Wouters, Carmen. 2015. "Towards a regulatory framework for microgrids - The Singapore experience." Sustainable Cities and Society 15:22-32.

Zell, Erica, Sami Gasim, Stephen Wilcox, Suzan Katamoura, Thomas Stoffel, Husain Shibli, Jill EngelCox, and Madi Al Subie. 2015. "Assessment of solar radiation resources in Saudi Arabia." Solar Energy 119:422-438.

Zhang, Fang, Hao Deng, Robert Margolis, and Jun Su. 2015. "Analysis of distributed-generation photovoltaic deployment, installation time and cost, market barriers, and policies in China." Energy Policy 81:43-55. 
Notes

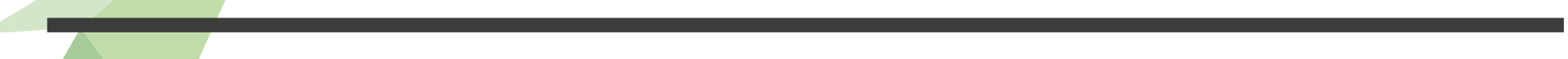




\section{Notes}




\section{Appendix A}

This section describes the steps undertaken to process the land-use data to produce the tables and figures presented above. Selected Python code snippets, as shown below.

\section{Acquire the landuse layer from RDA GIS Portal}

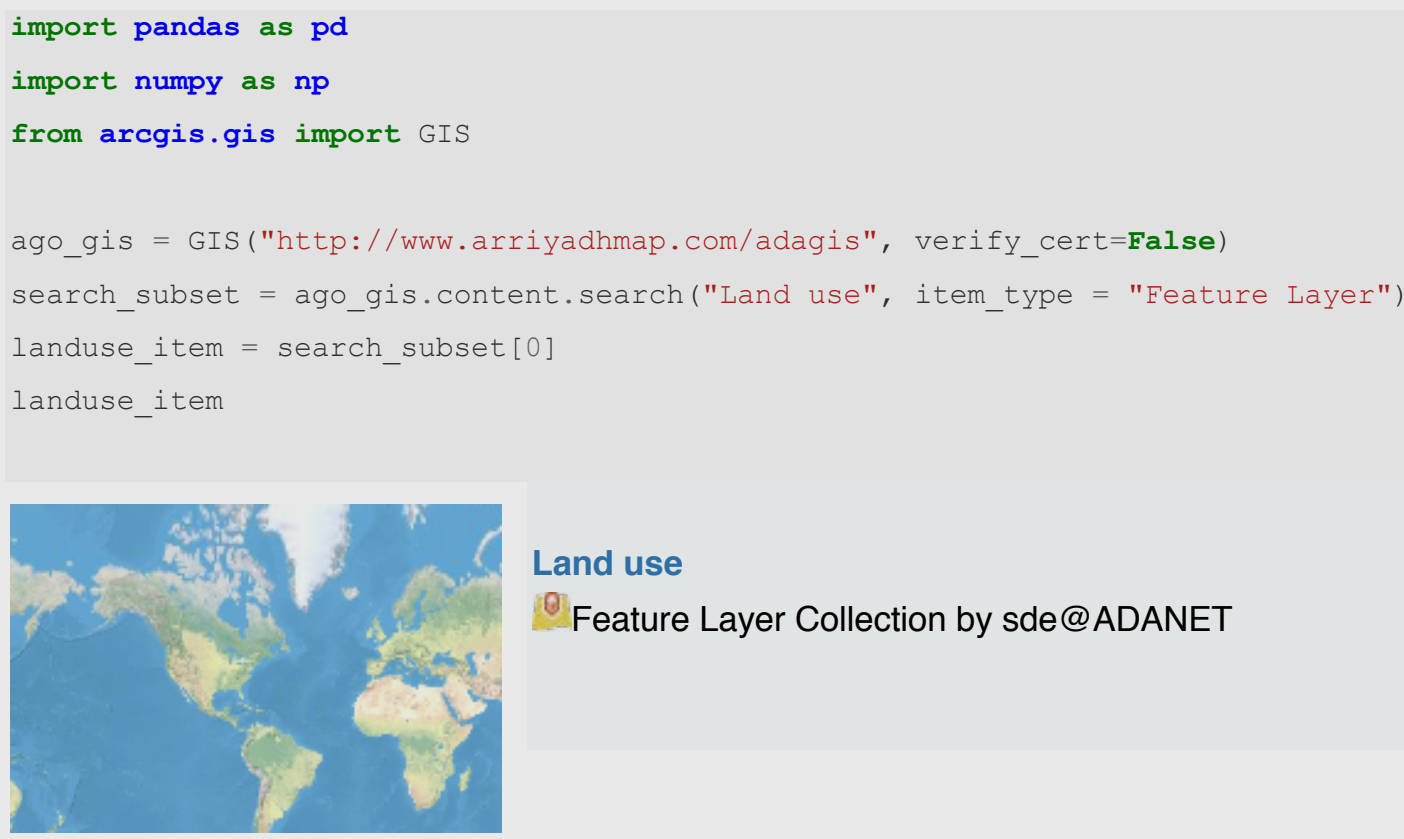

Open the above layer in ArcGIS Pro, add the land area attribute (in square meters) for each parcel by executing the "Add Geometry Attributes" tool. Then export the data into a tabular CSV format. It should be noted since most of the fields are populated in Arabic language, additional steps were also carried out to translate values in pertinent attributes, such as landuse code and building type, to English.

\section{Import raw landuse data as exported from GIS}

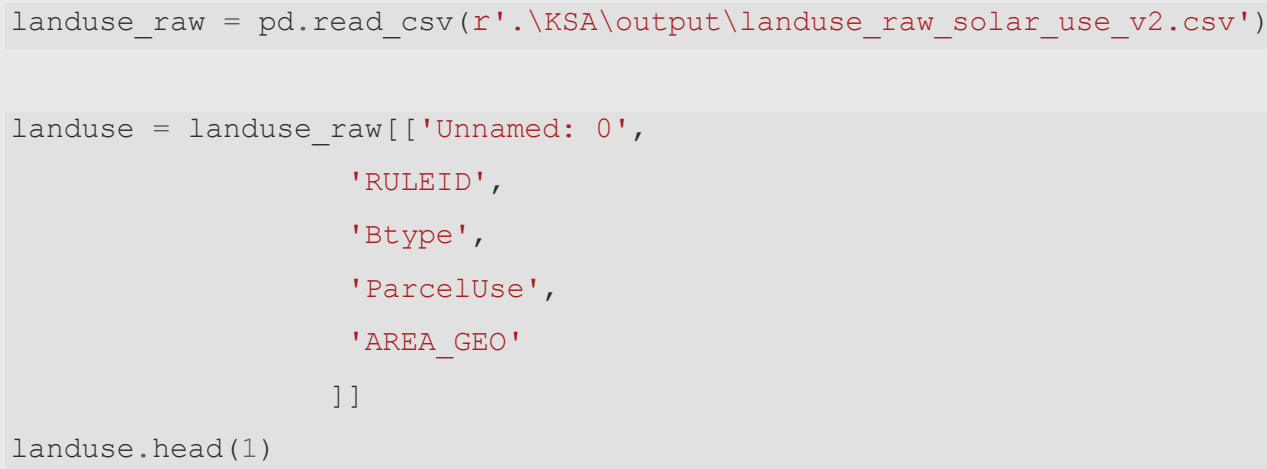

\begin{tabular}{llllll} 
& Unnamed: & RULEID & Btype & ParcelUse & AREA_GEO \\
\hline 0 & 0 & 1 & 4 & 1110 & 779.494
\end{tabular}




\section{Data Preparation - Step 1: Import landuse categories}

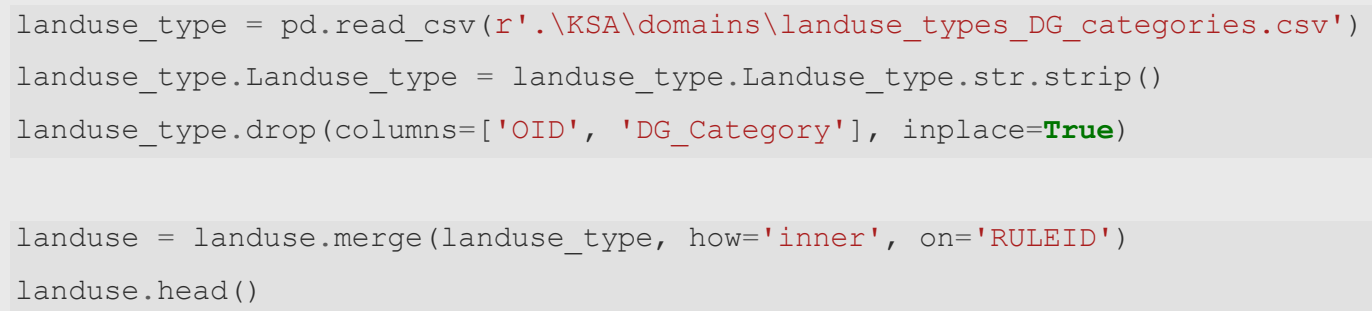

\begin{tabular}{llllcll} 
& Unnamed: 0 & RULEID & Btype & ParcelUse & AREA_GEO & Landuse_type \\
\hline $\mathbf{0}$ & 0 & 1 & 4 & 1110 & 779.494 & Residential \\
$\mathbf{1}$ & 1 & 1 & 4 & 1110 & 651.353 & Residential \\
$\mathbf{2}$ & 2 & 1 & 6 & 1110 & 724.642 & Residential \\
$\mathbf{3}$ & 3 & 1 & 4 & 1110 & 643.559 & Residential \\
$\mathbf{4}$ & 4 & 1 & 4 & 1110 & 1130.485 & Residential
\end{tabular}

\section{Data Preparation - Step 2: Import building types and detailed parcel use categories}

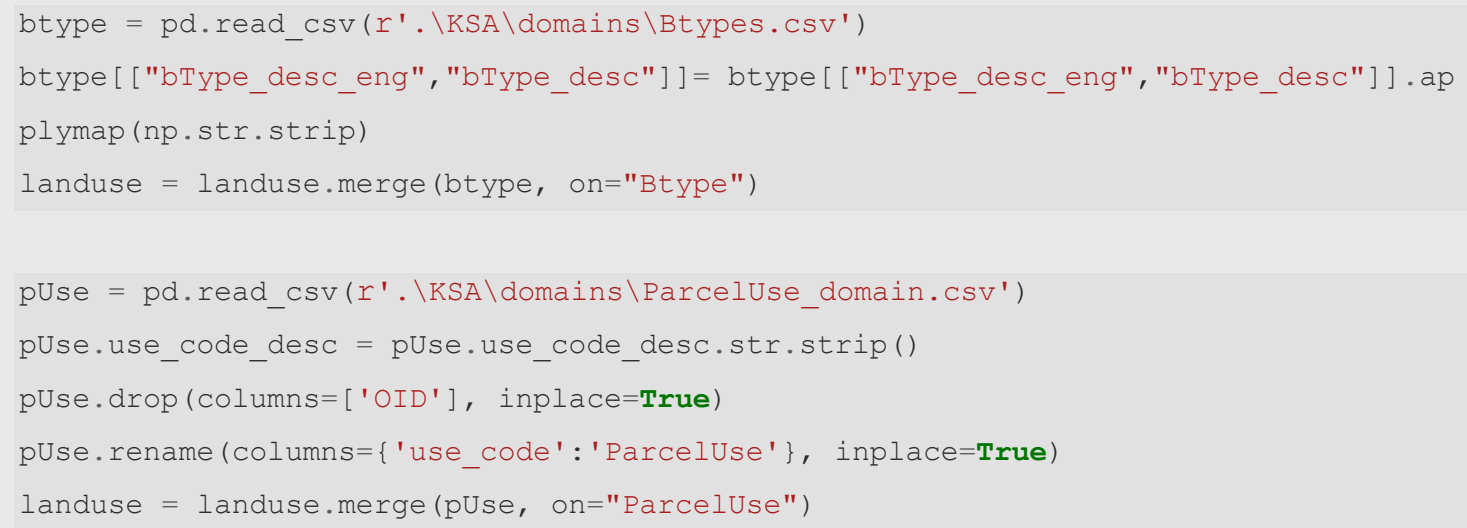

\begin{tabular}{lllllllll}
\hline $\mathbf{0}$ & $\mathbf{0}$ & 1 & 4 & 1110 & 779.494 & Residential & Villa & Villa/Apt \\
$\mathbf{1}$ & 1 & 1 & 4 & 1110 & 651.353 & Residential & Villa & Villa/Apt \\
$\mathbf{2}$ & 3 & 1 & 4 & 1110 & 643.559 & Residential & Villa & Villa/Apt \\
$\mathbf{3}$ & 4 & 1 & 4 & 1110 & 1130.485 & Residential & Villa & Villa/Apt \\
4 & 5 & 1 & 4 & 1110 & 1052.932 & Residential & Villa & Villa/Apt
\end{tabular}

* This column appears in Arabic in the original dataset, but was translated to English herein for convenience. 


\section{Data Preparation - Step 3: Rename fields and keep relevant fields only}

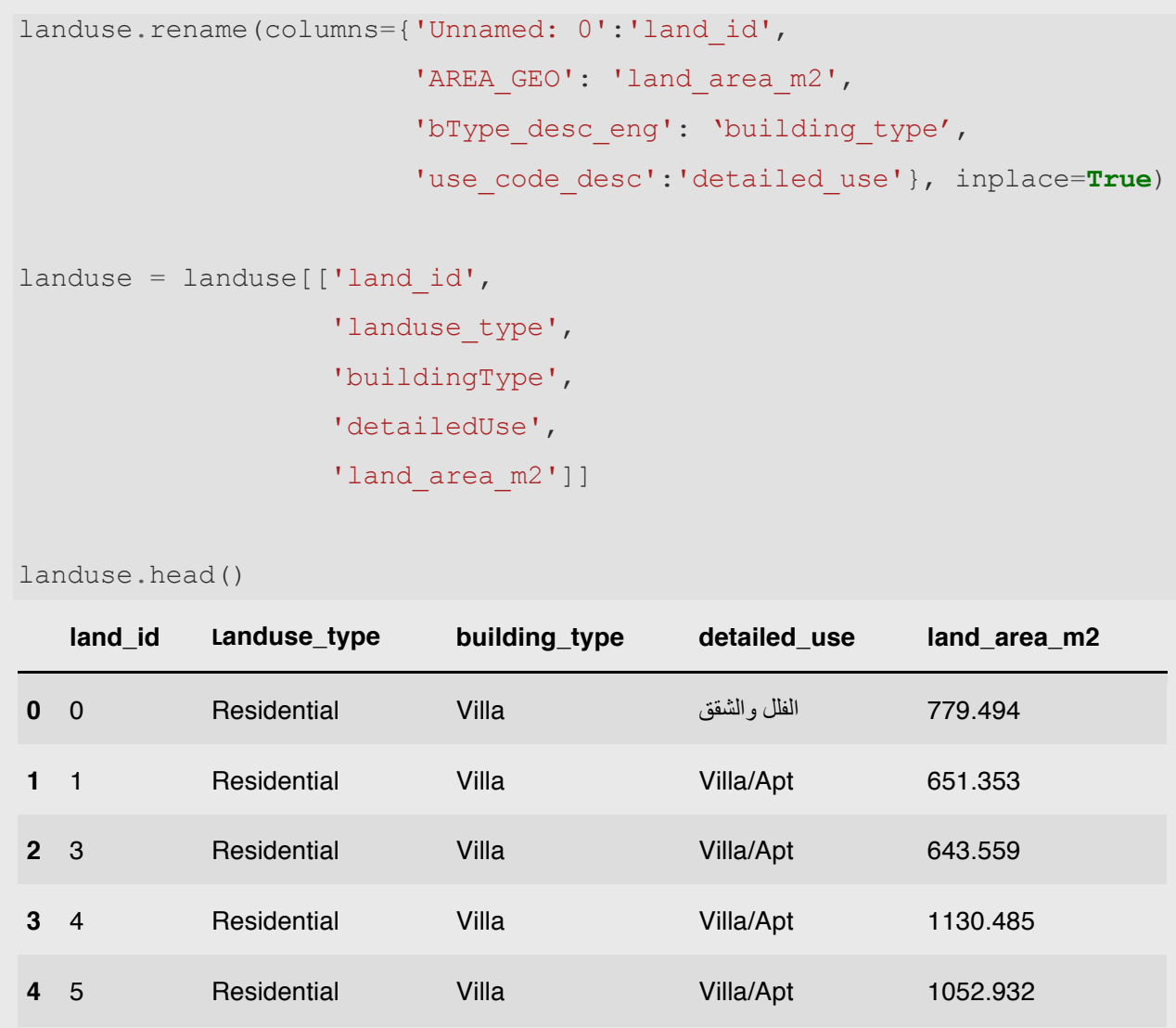

6. Data Preparation - Step 4: List unique landuse codes and building types (source of Tables 1 and 2)

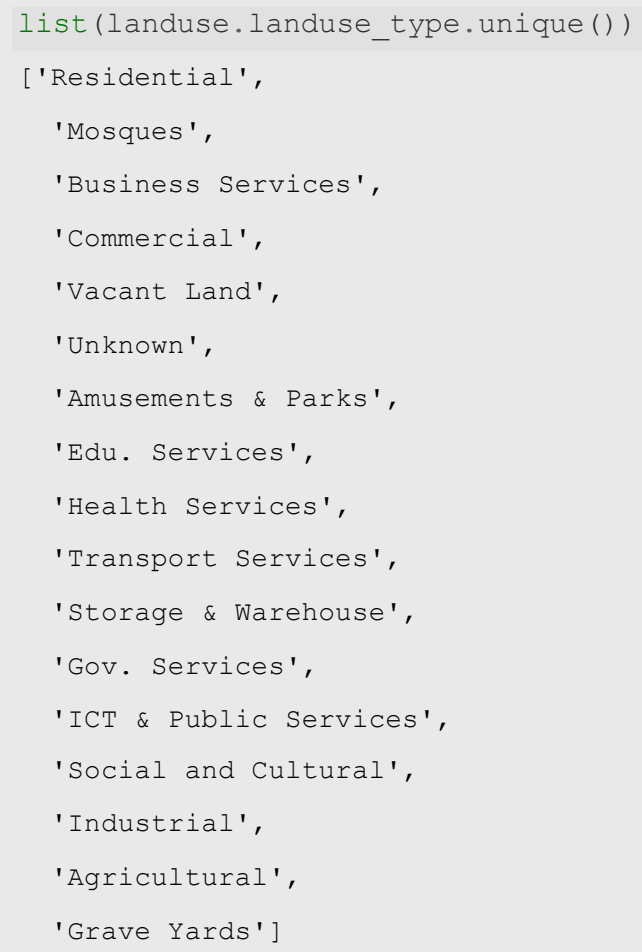




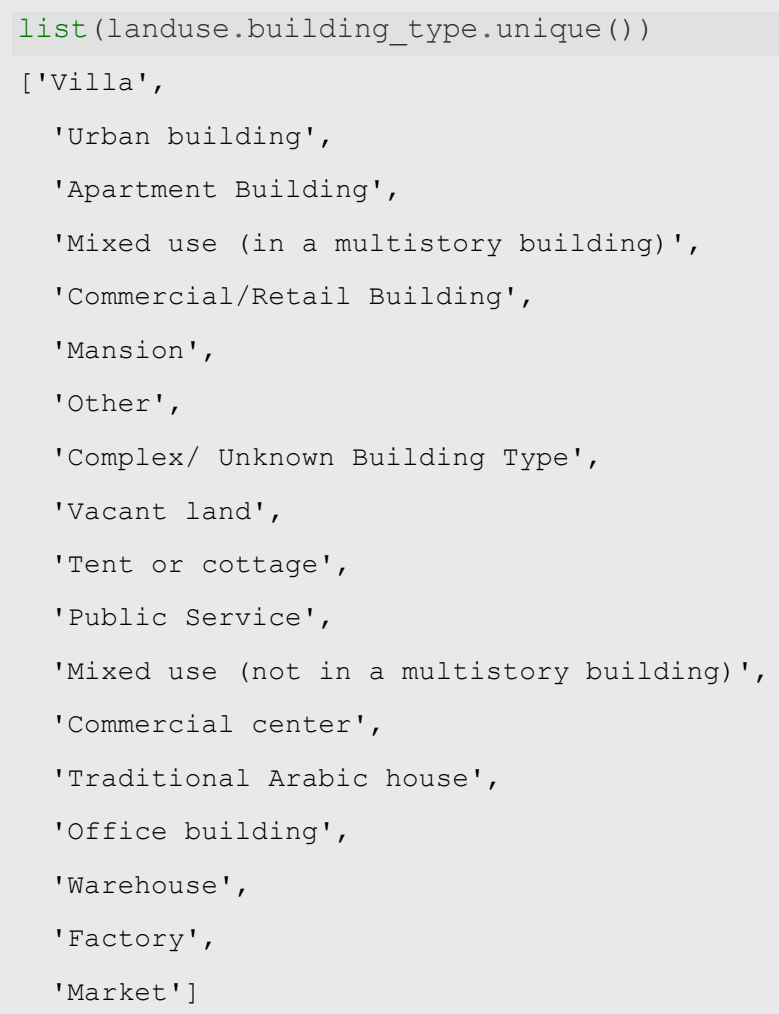

7. Data Preparation - Step 5: Filter out all parcels which are flagged with empty buildings, i.e., vacant

landuse $=$ landuse [landuse.building_type.str.upper() !='Vacant land'.upper() ]

8. Data Preparation - Step 6: Constrain the data to include only parcels with landuse_code tagged as Residential, Mosques, Commercial, and Health Services

landuse $=$ landuse [ landuse. landuse_type.isin ( ['residential','mosques','commercial','health services']

) ]

9. Aggregate the data based on landuse codes

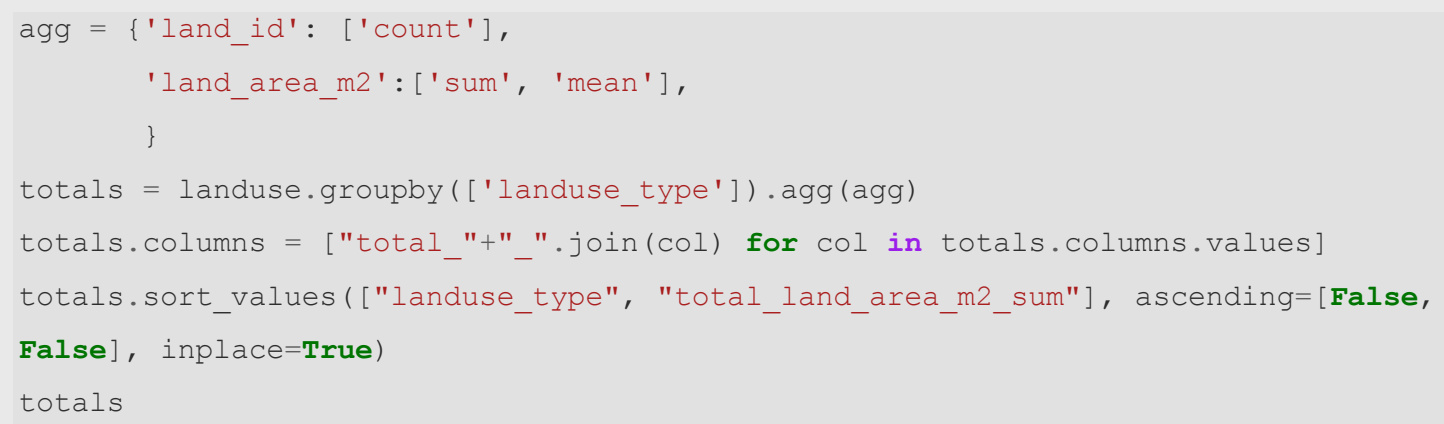


total_land_id_count total_land_area_m2_sum total_land_area_m2_mean

\begin{tabular}{|c|c|c|c|}
\hline landuse_type & & & \\
\hline Residential & 382472 & 272387977.486 & 712.178 \\
\hline Mosques & 4452 & 9675650.631 & 2173.327 \\
\hline Health Services & 826 & 7222285.302 & 8743.687 \\
\hline Commercial & 9441 & 22961228.784 & 2432.076 \\
\hline
\end{tabular}

\section{Aggregate the data based on landuse codes and building types}

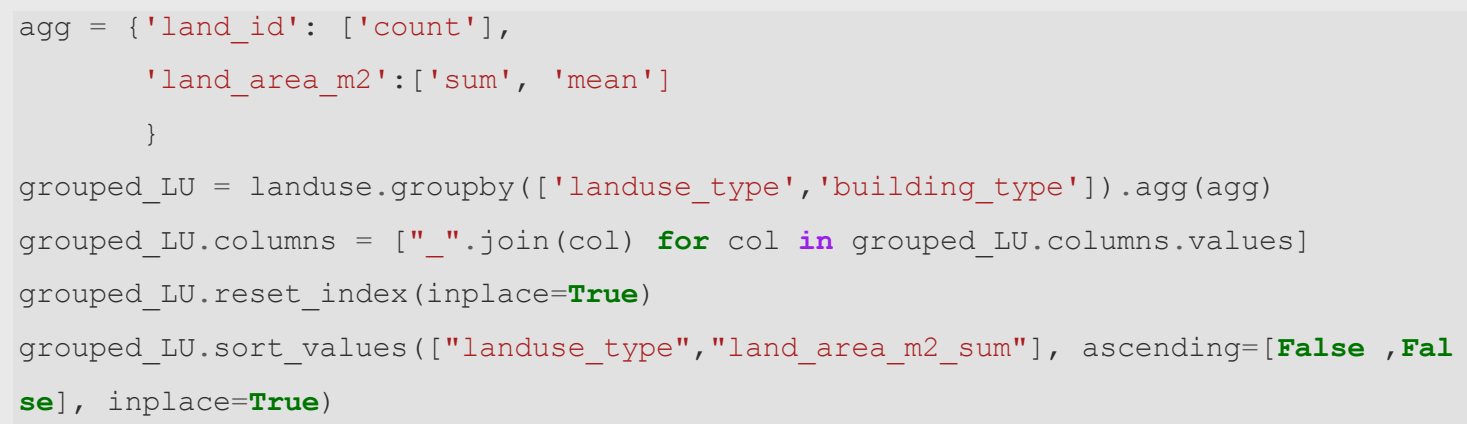

Through "grouped_LU" dataframe, we can compute the total land area occupied by the residential sector in Riyadh, particularly by: villas, mansions and apartment buildings.

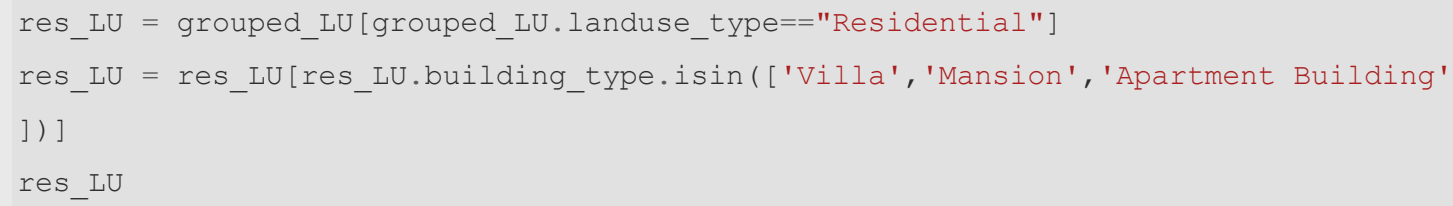

\begin{tabular}{llllll} 
& landuse_type & building_type & land_id_count & land_area_m2_sum & land_area_m2_mean \\
\hline $\mathbf{3 8}$ & Residential & Villa & 276862 & 171626280.502 & 619.898 \\
$\mathbf{4 0}$ & Residential & Apartment Building & 38009 & 22689745.934 & 596.957 \\
$\mathbf{3 9}$ & Residential & Mansion & 1688 & 17557757.849 & 10401.515
\end{tabular}




\section{Aggregate the data based on landuse codes and detailed use code}

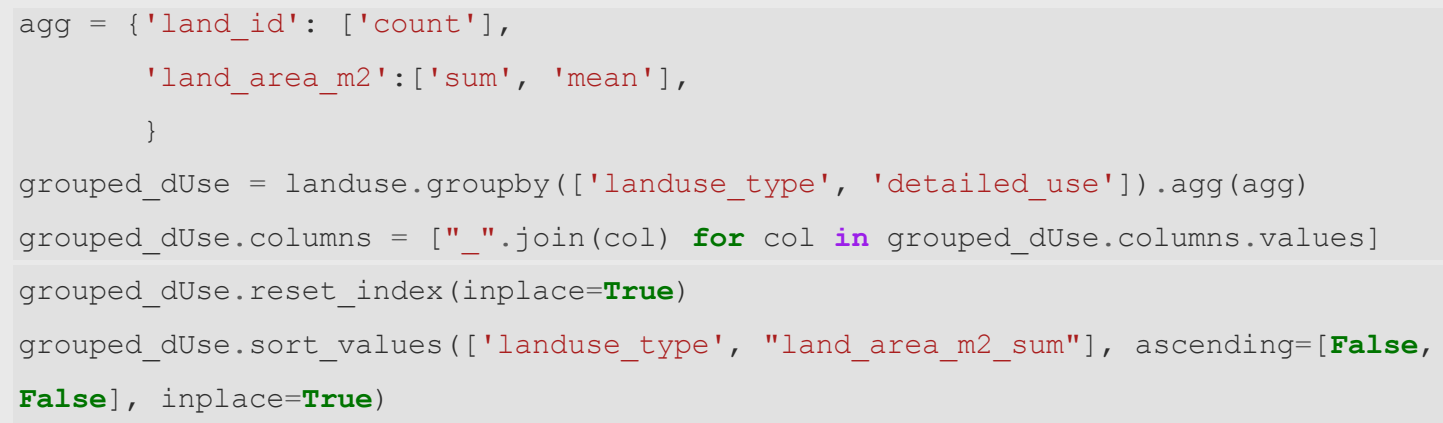

Through "grouped_dUse" dataframe, we can arrive at the total land area used for mosques in Riyadh.

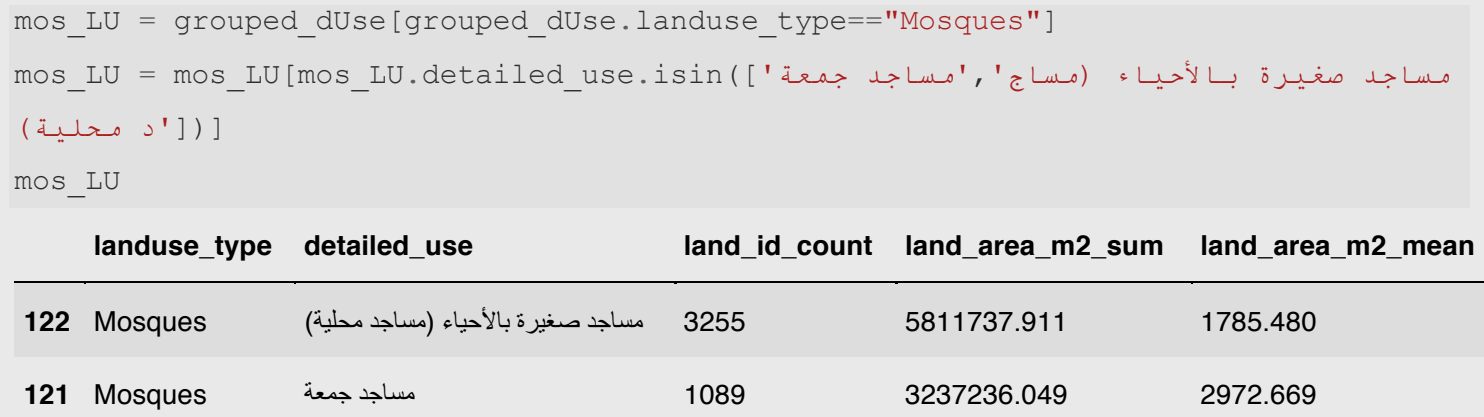

1089

3237236.049

2972.669

Similarly, total land area for malls (i.e., commercial buildings) and health services facilities, such as clinics, private and public hospitals can be calculated. 


\title{
About the Authors
}

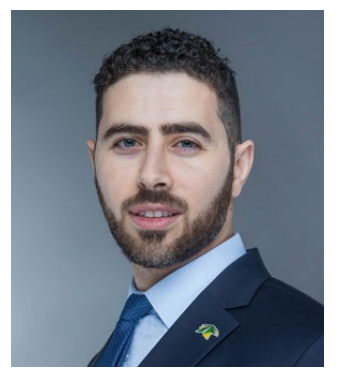

\author{
Abdelrahman Muhsen \\ Abdelrahman is a Senior Research Associate and a certified GIS \\ Professional (GISP). His research interests focus on transportation, \\ spatial analytics and geo-information management. He holds an \\ M.Sc. in Geomatics Engineering from the University of Calgary, \\ Canada.
}

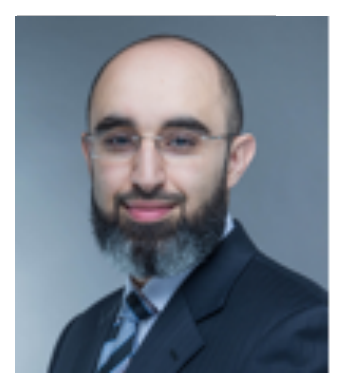

\section{Amro M. Elshurafa}

Amro is a Research Fellow working on energy transitions. His research interests include power system modeling, solar PV techno-economics, and hybrid microgrid design and optimization. The author of $40+$ papers and reports and the inventor of several patents, he holds a Ph.D. in electrical engineering and an MBA in finance.

\section{About the Project}

Rooftop solar photovoltaic (PV) systems, commonly referred to as distributed generation (DG) solar systems, can play a central role in the energy mix for sustainable cities. As with all forms of power generation, DG carries technical, financial, policy, and market implications that impact utilities, governments, businesses and other stakeholders. Therefore, quantifying the potential of DG for a given jurisdiction helps to inform the decision-making process for all involved.

To this end, this study quantifies the upper limit of rooftop PV systems that could be deployed in Riyadh, the capital of Saudi Arabia, using geographic information system (GIS) analysis. The study utilizes a data set of nearly 1 million land lots in combination with land-use categories, building types, and relevant building codes. The research finds a maximum potential capacity of 4.34 gigawatts (GW), representing nearly $22 \%$ of central Saudi Arabia's peak load and can satisfy approximately $9 \%$ of the region's total energy requirement. 
INAPSARC

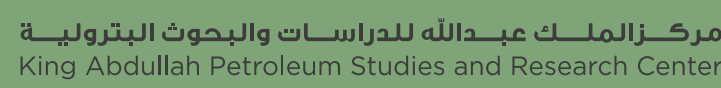

www.kapsarc.org 